\title{
Students' Learning Assessment Practices Used by Jordanian Teachers of Mathematics for Grades (1-6)
}

\author{
Eman Rasmi Abed ${ }^{1} \&$ Ferial Mohammad Abu Awwad ${ }^{2}$ \\ ${ }^{1}$ Faculty of Educational Sciences and Arts, UNRWA, Amman, Jordan \\ ${ }^{2}$ Educational Psychology Department, The University of Jordan, Amman, Jordan \\ Correspondence: Eman Rasmi Abed, Faculty of Educational Sciences and Arts (UNRWA), Amman, Jordan. Tel: \\ 9-626-534-8486. E-mail: eabed67@yahoo.com
}

\author{
Received: June 5, 2015 Accepted: August 10, 2015 Online Published: December 28, 2015 \\ doi:10.5539/ies.v9n1p63 URL: http://dx.doi.org/10.5539/ies.v9n1p63
}

\begin{abstract}
This study aims to investigate the students' learning assessment practices used by Jordanian teachers of mathematics for grades (1-6) in Amman. The sample of the study consists of (402) teachers. A questionnaire of (72) items are developed on four domains, namely: questions, homework, exams, and alternative strategies. Validity and reliability are established. Results of the study show that the mean of the scores for the four domains and the entire items are medium, the highest was on exams and the lowest on the homework. ANOVA analysis show that there were no statistically significant differences related to number of courses and gender. On the other hand, there are statistically significant differences on the scientific qualification in favor of postgraduate studies. As for the type of school, the results are in favor of government schools. In regard to the number of experience years, the results are in favor of category (5-10) years on homework domain only.
\end{abstract}

Keywords: alternative assessment, assessment practices, exams, homework, Mathematics teachers, questions

\section{Introduction}

Evaluation is one of the educational processes that aim to enhance learning, especially when used in authentic contexts. Students are expected to demonstrate learning by performing meaningful tasks. Meaningful assessment can provide teachers with useful and clear information about their students such as the areas of misunderstanding in students' learning, and corrective feedback for further instruction leading to developing instruction that improve learning. Engaging students in meaningful tasks and encouraging them to share their work by discussing and talking about their learning processes results from the meaningful context used for assessment. It is all about students taking an active part and being involved in in the process of assessment. Understanding the details of assessment; the criteria and the processes enables the students to possess the ability to assess their own work by developing self-assessment skills. Independent life-long learners who are able to regularly monitor and assess their own progress is considered the ultimate goal of assessment.

Teachers are the primary assessors inside the classroom who usually use the tools of assessment in order to get information about teaching and learning, in addition to monitoring students' progress in achieving learning objectives. Their role in this side exceeds just assisting students to develop self-monitoring and self-assessment skills and strategies, teachers work on driving their students to be involved in setting learning outcomes, developing plans, and using alternative strategies in monitoring their own achievement. Furthermore, teachers watch students' learning and progress by observing them regularly and systematically in classrooms by interacting with them while teaching. Teachers collect data by observing and assessing students' interaction, performance, and projects or work samples, and making judgments based on these observations demonstrating that assessment is an essential part of the learning process. The effective alternative strategies they model in the classroom lead to involve the students in the procedures of developing assessment such as preparing rubrics and checklists. In addition to interaction with students in the classroom regarding students' assessment, teachers collaborate with parents and colleagues. In recent years, educators have been urged to use a wider variety of measuring and testing devices other than the traditional paper-and-pencil tests, quizzes and examinations (Eggen \& Kauchack, 2004).

Alternative assessment and testing practices associated with it have recently been used in math testing. They are 
directed to establish qualitative, more democratic, and task-based methods of evaluation in testing learner's proficiency in math. It contrasts with traditional methods of testing by exams, and helps involving the students in the evaluation process, and locating evaluation in a real-life context. Thus, the insights emanating from these methods being used for decision-making about student's achievement in math contribute to and furnish for additional instructional purposes. The procedures used include checklists, journals, logs, videotapes and audiotapes, self-evaluation, teacher observations, portfolios, conferences, diaries, self - assessments and peer-assessments. These procedures are called alternative or performance assessment as opposed to traditional assessment techniques (Kizlik, 2012).

When these assessment procedures are conducted appropriately, they will help students to learn math in a meaningful way and encourage their motivation to learn. Assessment can be used to improve the quality of learning and math instruction. It provides important feedback on the progress and helps students to realize their points of strength and weakness without being judgmental. Effective assessment provides the necessary information to decide how a student is progressing with his/her learning. Appropriate assessments can encourage deep rather than shallow approaches to learn math (Lamprianou \& Athanasou, 2009).

Research on the assessment practices of teachers at school has been conducted by a number of researchers. Studies have examined how teachers assess student performance in the classroom, the use of traditional and alternative assessment procedures in the classroom, the relationships between grade level, subject taught and assessment practices of teachers, teachers perceived level of preparedness for using classroom assessment, and the in-service needs of teachers. Stiggins, McMillan, Nash and Mertler have attempted to define what the quality classroom assessment looks like and what teachers are actually doing in their classrooms (Mckenna, 2004).

Campbell and Evans (2000) and Green and Mantz (2002) found that teacher-prepared paper-and-pencil assessments are often fraught with unacceptable levels of measurement error. Their findings are important because teachers reported using tests as a primary indicator of student achievement. Therefore, the use of inadequate and potentially invalid tests contributes toward the measurement errors resulted from using inappropriate assessments procedures to render important decisions regarding student learning.

Brookhart (2001) summarized teacher competence in classroom assessment. The results found that teachers lack proficiency in test construction and do not always use valid grading methods. In addition, they have difficulty interpreting standardized tests. This incompetence can affect student's learning and result in inaccurate evaluations of their learning and achievement.

Wikström's (2007) study aimed at determining what alternative assessment techniques were practiced in a public school with an international program, and exploring the teachers' attitudes towards the use of alternative assessments procedures. Results showed that various types of assessment strategies were needed to be utilized in order to evaluate students' needs, and that those alternative assessment procedures have a positive role by meeting the students' needs in supporting the learning process.

Culbertson and Wenfan (2003) conducted a study on the primary grade literacy teachers' attitudes towards practices of alternative assessment strategies. They found that teachers' practices in alternative assessments increased in the presence of administrative support, availability of sufficient resources, scholarly reading, and the professional freedom to choose assessment techniques.

\subsection{Literature Review}

Albursan and Tighza (2012) conducted a study aimed to analyze the evaluation activities which were implemented by the mathematics teachers of the Saudi Arabian sample in the international study "Trends In Mathematics and Science Study(TIMSS) 2007", and comparing it with the evaluation activities which were implemented by mathematics teachers of the Republic of Korea sample in that study, and to determine the relationship between the evaluation activities and the students' achievement in the achievement tests. The analyzed data consisted of the responses of (171) 8th grade mathematics Saudi Arabian teachers and the responses of (242) 8th grade mathematics South Korean teachers who filled the Teacher Background Questionnaire related to TIMSS study. The results indicated that there were differences in the evaluation between the teachers of the Saudi Arabian sample and the teachers of Republic of Korea sample in the frequency of the home works and its implementation times. The Saudi teachers indicated that they give more home-work, and the Korean participants indicated that their students' implementation time of the home-work is longer. In terms of classroom questions and their strategies, the Korean teachers indicated that they allow students to answer questions independently more than their Saudi counterparts. There also were differences between the two samples in terms of the questions types (selected response vs constructed response), and the cognitive levels which they measure. The Korean teachers appear to focus more on higher order thinking than lower order 
thinking questions.

In addition to that, there were differences in using the authentic assessment strategies and its tools. The study recommended training of Saudi Arabian mathematics teachers on authentic assessment strategies, construction of questions tapping on higher order thinking parallel to the released versions of the TIMSS questions.

Rodriguez (1999) research aimed to examine the relationship between students' achievement in mathematics in (TIMSS, 1995) and the number of times of evaluation, and the reason for using the evaluation tools such as providing feedback and educational diagnosis, in addition to the link between the teachers' evaluation experience and student achievement in mathematics in large-scale tests using students' questionnaire data and teachers' questionnaire data, and students grades in (TIMSS, 1995). Evaluation tools were divided into two facets: the first was homework of two dimensions on the type of the task and the repetition of either the objective of providing feedback or the objective of students' grading, the second was about the alternative tools and also had two dimensions: multiple-choice questions and short-answer questions with the projects. Correlation coefficient between times of repetition of setting homework in order to provide feedback and achievement in math test was positive and weak $(r=0.12)$ while the correlation coefficient between the times of repetition of setting homework in order to grading students and achievement in math test was positive and very weak $(r=0.06)$, the correlation between the number of times of using multiple-choice questions and short-answers questions with the achievement in mathematics was negative and weak $(\mathrm{r}=-0.16)$, and also found that the correlation between the frequency of using each of short-answer questions and projects and note-making were close to zero (respectively: $\mathrm{t}=0.04, \mathrm{t}=-0.01, \mathrm{t}=-0.06)$.

Cizek (2009) confirms that extensive test reports containing evidence of students' achievement are reports of a holistic judgment of classroom evaluation that provide quality information, which is not always guaranteed. Teachers' multiple-choice test which aims to diagnose is a critical task and does not always ensure rising of students' achievement, but suitable content can improve achievement in large-scale tests. For feedback, which can be defined as a part of the specific and constructive ongoing conversation about the learning that is directly related to the results of the learner, (Alberta Assessment Consortium, 2005)) have positive impact on students' performance on the tests in general, including large-scale tests. Homework as one of assessment activities contributes in facilitating learning; in other words, it has an impact on the teaching learning process as mentioned in many studies (Mikk, 2006). Homework also has an effect not only on students' achievement but also on students' development in general, for it affects future learning behavior, positive scientific power, motivation, personal effectiveness, responsibility awareness, and other personal features related to achievement (Zimmerman \& Kitsantas, 2005).

Dweik (2009) aimed at investigate the degree of math teachers' knowledge of concepts, strategies, tools of realistic assessment, and the degree of application, and study the relationship between the teachers' knowledge and application of realistic assessment strategies and its tools at UNRWA in Zarka District. To achieve the goals of the study, two instruments were designed and developed: one to measure the degree of teachers' knowledge of concepts, strategies, and tools of realistic assessment, and an observation card to measure the degree of teachers' application of realistic assessment tools and strategies. Results showed that the degree of math teachers' knowledge of concepts, strategies and tools of realistic assessment tools was medium, and the results of observation card revealed that the degree of math teachers' application of realistic assessment strategies was rather low. The results also reflected that the relationship between the degree of math teachers' knowledge of realistic assessment strategies and tools and their degree of practice was weak.

Jackson (2009) implemented a study on the elementary teachers' classroom assessment practices and the powers that influence their assessment decision. Findings revealed that significant use of traditional assessment methods, mostly multiple choice tests in both formative and summative manners were used to modify instruction and progress reports. Internal and external factors found to influence the teachers' choice of traditional assessment practices. These factors vary between high-stakes tests, teachers' beliefs and values, ease of development and scoring, and perceived the need for documentation, with other social and institutional structures that influence teaching practices.

Cooper, Robinson, and Patal (2006) summarized studies conducted in the United States since 1987 on the effect of homework on students' achievement. The results revealed that regardless of the design, consistent evidence of positive influence of homework on students' achievement was found in all grades.

Cooper and Valentine (2001) indicated that homework that needs less than (10) minutes or one to two hours has no significant relationship with achievement while homework that needs (10-60) minutes has a positive relationship with achievement. 


\section{Comments on the review}

Topics related to the methods of assessment and strategies of evaluation were dealt with through the review of related literature. In addition to the possessing of the teachers to the concepts and strategies of assessments, the degree of applying these strategies in their practices in evaluating and analyzing tests are also observed. It is noticed that some studies dealt with the used assessment practices and their impact on teachers and students; some dealt with teachers' evaluation linking it with other concepts while some investigated realistic/alternative evaluation and its methods and obstacles that limit its application, and the degree of teachers and students' understanding of these concepts such as the study of Dweik (2009) with variance in the results between them.

The current study is an extension of the previously mentioned studies in terms of highlighting the evaluation practices for mathematics teachers' perspectives where its significance stems from its instrument being a comprehensive tool that includes assessment tools. Previous studies have been beneficial in the interpretation and discussion of results.

\subsection{Research Problem and Its Questions}

Nature of mathematics tends to the abstract side of cumulative and constructive nature as the basic skills in mathematics are established in the basic classes of the first stage then to be built upon in subsequent grades. This special nature of mathematics requires diverse and different assessment practices to measure skills and learning outcomes that have been achieved in each classroom and across different grades. As the educational reform movement is interested in improving the reality of the educational process, calls for the diversification of instructional strategies and the evaluation process, this study tends to detect the assessment practices of mathematics teachers used by teachers in grades one to primary six.

Specifically tried to answer the following questions:

- What is the students' learning assessment practices used by Jordanian teachers of mathematics for grades (1-6) in each domain of the following: questions, exams, homework, and alternative strategies?

- Are there any statistically significant differences in the students' learning assessment practices used by Jordanian teachers of mathematics for grades (1-6) that are attributed to the teacher's gender (male and female), teacher's qualification (bachelor, high studies), school type (public, private), training sessions (none, 1-3, more than 3), and experience years (less than5, 5-10, more than 10)?

\subsection{Research Objectives}

This study aims to:

- Investigate the students' learning assessment practices used by Jordanian teachers of mathematics for grades (1-6).

- Investigate the differences of assessment practices in light of the variables (gender, qualification, school type, number of training session, and experience).

\subsection{Significance of the Study}

Different types of assessment practices have great importance in bringing about changes in the learning process, and through the access to assessment practices applied by mathematics teachers during their teaching; a clear picture of the reality of teaching is gained. This discipline allows the opportunity to guide the evaluation practices of teachers and identify the strengths and weaknesses of these practices in order to be used as a guiding reference by in the preparation of teacher training programs in accordance with their actual needs. They can be utilized to identify the training needs for teachers of mathematics in the field of measurement and evaluation.

This study enables supervisors and managers to have a clear vision about the actual status of the assessment practices of mathematics teachers, helping them to implement development and development plans for the teachers, which may allow for the appearance of new practices. The study provides an opportunity of diversification in the use of evaluation techniques as this study contributes to allow researchers develop new titles that could be stemmed from this study.

\subsection{Limitations of the Study}

Results of this study are limited to:

Human Limitation: The study is limited to all mathematics teachers in these schools.

Instrument of the study: A questionnaire developed by the researchers was used, and psychometric properties were verified. 


\subsection{Research Operational Definition of Terms}

Mathematics teacher: is the person who is responsible of teaching Mathematics in educational institutes and holds a bachelor degree as a minimum requirement.

Assessment practices: A group of methods and practices that enables the assessor to collect data in order to form judgments used in taking the suitable decisions and certain judgments that help in evaluation (Abu Zeina, 1998, p:198). The operational definition is that it refers to a group of strategies that go in agreement with modern trends in assessment, integrated with the teaching process and reflects and measures the students' performance. It includes the strategies: paper and pencil assessment, observation, performance, communicative, and self-review.

Assessment tools: A set of tools intended to collect information and data through the individuals, such as observation tools self-assessment tools. (Publications of Al-Quds Open University, 1998, p. 177). Operationally, they are defined as a set of tools and methods used by mathematics teachers to measure the performance of their students and to take the necessary educational decisions.

Basic educational stage: It's an educational stage ranging from first basic grade to tenth basic grade, and it is considered the educational base for building national unit in development of abilities and self-tendencies. It is a mandatory phase. Operationally, it is defined as the procedural stage of classes from the first to the sixth primary.

\section{Method}

\subsection{Participants}

The study included (402) teachers of mathematics at Jordanian schools, they were selected randomly and distributed on the following variables: gender, qualification, school type, training sessions, and experience years as shown in Table 1.

Table 1. Distribution of participants

\begin{tabular}{lll}
\hline Gender & male & 134 \\
& female & 268 \\
Total & & 402 \\
Qualification & Bachelor & 290 \\
& M.A \&PhD & 112 \\
Total & & 402 \\
School type & Public & 330 \\
& Private & 72 \\
Total & & 402 \\
Experience years & Less than 5 & 172 \\
& $5-10$ & 124 \\
Total & More than 10 & 106 \\
Training course & & 402 \\
& None & 132 \\
& $1-3$ & 226 \\
Total & More than 3 & 44 \\
\hline & & 402 \\
\hline
\end{tabular}




\subsection{Instrument}

A questionnaire was prepared to examine the assessment practices of student learning as follows:

With reference to the reviewed theoretical and empirical literature and what was mentioned in the scientific resources about the assessment practices of the teachers, these practices were summarized in four key domains as follows: the questions, homework, tests, and evaluation performance assignments. Items were structured according to each domain.

The questionnaire consisted of (72) items, distributed into four domains: questions (14) items, homework (16) items, exams (26) items, and alternative strategies (16) items. It was organized in a Likert rating scale of five categories (very high, high, medium, low, and very low).

\subsubsection{Validity}

Questionnaire validity was verified by (8) arbitrators from supervisors and faculty members. They provide some comments and suggestions related to language expressions, and then the questionnaire was modified to fit these comments. Comments of the jury were concerned only about linguistic and grammatical mistakes, and the number of the items remained (72) as designed.

A pilot study was carried out on a sample of (20) teachers. Validity was assured by finding correlation coefficients between the grades and scores on the paragraphs of the domains that valued (0.36 and 0.76), all of which are statistically significant.

\subsubsection{Reliability}

To investigate reliability, the questionnaire was applied on a sample of (20) teachers out of the participants. Internal Consistency was calculated through Cronbach's Alpha Coefficient, it was 0.98 for the whole questionnaire. Reliability of the sub domains ranged between 0.91 and 0.95 . Table 2 showed these results.

Table 2. Cronbach's alpha coefficient for each domain and for the whole questionnaire

\begin{tabular}{lcc}
\hline Domains & Number of items & Alpha co. \\
\hline Questions & 14 & 0.91 \\
Homework & 26 & 0.94 \\
Exams & 16 & 0.94 \\
Assessment strategies & 16 & 0.95 \\
Total & 72 & 0.98 \\
\hline
\end{tabular}

\section{Results}

First question: What are the assessment practices of students' learning used by Jordanian teachers of mathematics for grades (1-6) in each domain of the following: questions, exams, homework, and alternative strategies?

Means and standard deviations were calculated for each item and the overall score of the questionnaire. Items were ranked according to their means in a descending order as shown in table 3. Means were categorized into three levels: low (1 to 2.33 ), medium (2.34 to 3.66), and high (3.67-5).

Table 3. Means and standard deviations for items, domains, overall questionnaire and level of each

\begin{tabular}{llclc}
\hline $\begin{array}{l}\text { Item } \\
\text { No. }\end{array}$ & Items & Mean & $\begin{array}{l}\text { Std. } \\
\text { Deviation }\end{array}$ & Level \\
\hline First domain: questions & & & \\
11 & $\begin{array}{l}\text { I supervise my students while doing the exercises and answering the } \\
\text { questions. }\end{array}$ & 4.32 & .75 & High \\
3 & I raise oral questions while presenting the lesson. & 4.19 & .86 & High \\
2 & I ask questions that reveal the previous learning. & 4.10 & .79 & High \\
\hline
\end{tabular}




\begin{tabular}{ll}
\hline 13 & I answer all my students' questions. \\
5 & I raise questions that require written answers. \\
1 & I plan for the questions I'll ask in the classroom \\
12 & I ask questions depending on student's level. \\
4 & $\begin{array}{l}\text { I use classroom questions to construct mathematical knowledge for } \\
\text { students. }\end{array}$ \\
8 & I ask questions that motivate students' thinking. \\
14 & I ask questions at the end of the lesson that introduce the new one. \\
7 & I ask open answer questions in the classroom. \\
6 & I ask questions that need group work. \\
9 & I ask questions that need some research to answer. \\
10 & I don't ask students to do written tasks and exercises in the
\end{tabular}

3.97

$3.92 \quad .98$

$3.90 \quad .87$

$3.75 \quad 1.01$

$3.73 \quad .88$

$3.49 \quad .95$

$3.27 \quad 1.15$

$3.12 \quad 1.23$

$3.09 \quad 1.17$

$2.92 \quad 1.24$

$2.48 \quad 1.31$

$4.13 \quad .90$

$3.81 \quad .93$

$3.51 \quad 1.12$

$3.33 \quad 1.17$

$3.30 \quad 1.20$

$3.26 \quad 1.08$

$3.23 \quad 1.13$

$3.21 \quad 1.13$

$3.19 \quad 1.12$

$3.18 \quad 1.22$

$3.17 \quad 1.23$

$3.10 \quad 1.15$

$2.83 \quad 1.48$

$2.81 \quad 1.35$

$2.67 \quad 1.34$

$2.56 \quad 1.38$

$4.03 \quad 1.01$

$3.99 \quad .97$

$3.92 \quad 1.03$

$\begin{array}{ll}3.88 \quad .83 \\ 3.85 & 1.03\end{array}$

$3.85 \quad 1.03$

$3.79 \quad .98$

$3.79 \quad .98$

$3.77 \quad .93$
High

High

High

High

High

Medium

Medium

Medium

Medium

Medium

Medium

High

High

Medium

Medium

Medium

Medium

Medium

Medium

Medium

Medium

Medium

Medium

Medium

Medium

Medium

Medium

High

High

High

High

High

High

High

High 


\begin{tabular}{ll}
\hline 48 & I include my exams different types of questions to cover all levels of \\
the cognitive domain. \\
42 & I include my exams some mathematical exercises. \\
53 & I put a total grade for the essay question answer. \\
44 & I explain the results of my students' exams. \\
47 & I give a written feedback on exams paper. \\
39 & I train my students on questions similar to those of the exam. \\
35 & I use the book's questions in my exams. \\
54 & I prepare a detailed key answer for each essay question. \\
37 & I record each student's mistakes separately. \\
40 & I prepare a table of specifications before writing the final exams. \\
51 & I use questions that integrate mathematical knowledge with the real \\
52 & $\begin{array}{l}\text { life. } \\
49\end{array}$ \\
$\begin{array}{l}\text { I use different resources to search for my exam questions. } \\
\text { the exams. }\end{array}$ \\
55 & $\begin{array}{l}\text { I get coefficient of the difficulty and discrimination of my questions } \\
\text { before giving the exam }\end{array}$ \\
50 & I give the exam again to the student of low achievement. \\
38 & I prepare different forms of the exam. \\
34 & My exams include only one type of questions. \\
41 & I do not pay much attention to the difficulty or ease of the exams'
\end{tabular}

$\begin{array}{lll}3.72 & 1.01 & \text { High } \\ 3.66 & .91 & \text { Medium } \\ 3.61 & .85 & \text { Medium } \\ 3.61 & .91 & \text { Medium } \\ 3.59 & 1.08 & \text { Medium } \\ 3.59 & 1.12 & \text { Medium } \\ 3.48 & 1.09 & \text { Medium } \\ 3.44 & 1.13 & \text { Medium } \\ 3.40 & 1.10 & \text { Medium } \\ 3.32 & 1.30 & \text { Medium } \\ 3.31 & 1.08 & \text { Medium } \\ 3.27 & 1.18 & \text { Medium } \\ 2.99 & 1.16 & \text { Medium } \\ & & \\ 2.94 & 1.26 & \text { Medium } \\ 2.88 & 1.28 & \text { Medium } \\ 2.83 & 1.40 & \text { Medium } \\ 2.74 & 1.23 & \text { Medium } \\ 2.59 & 1.33 & \text { Medium }\end{array}$

\section{Fourth domain: alternative strategies}

$58 \quad$ I use the observation strategy in evaluating my students.

57 I believe that it's important to use different alternative strategies besides exams.

$3.98 \quad .87 \quad$ High

$3.90 \quad .94 \quad$ High

64 I use checklist as a tool to assess my students' performance.

$3.84 \quad 1.14$

High

65 I use the rating scale to assess my students' performance.

$3.77 \quad 1.18$

High

60 I use the performance alternative strategies to assess my students.

$3.54 \quad 1.04$

Medium

61 I use the communication strategy to assess my students.

$3.48 \quad 1.04$

Medium

70 I depend on the performance assessment in assessing my students.

$3.47 \quad 1.09$

Medium

I prefer the cumulative assessment in the final assessment.

$3.45 \quad 1.07$

Medium

68 I observe my students' writing.

$3.34 \quad 1.19$

Medium

62 I use my student diary to assess them.

$3.13 \quad 1.27$

Medium

69 I use power point presentation to assess my students' performance.

$3.07 \quad 1.29$

Medium

59 I let my student write their impression concerning their work.

$3.04 \quad 1.21$

Medium

63 I use anecdotal record to assess my students.

$3.02 \quad 1.33$

Medium

66 I give my students the chance to share in deciding the criteria I use in the rating scale and the checklist.

Medium

67 I give my students the opportunity to choose their assessment style.

$2.77 \quad 1.35$

Medium 


\begin{tabular}{llll}
\hline third domain: exams & 3.60 & 0.63 & Medium \\
fourth domain: alternative strategies & 3.56 & 0.83 & Medium \\
Overall total questionnaire & 3.40 & 0.64 & Medium \\
\hline
\end{tabular}

Results in Table 3 revealed the following:

According to the first domain (Questions), the item "I supervise my students while doing the exercises and answering the questions" had the highest mean among the items in the domain while the item "I don't ask students to do written tasks and exercises in the classroom" had the lowest mean.

There were (8) items that got high level of practice, and (7) items got medium level of practice, but there weren't any item that got low level of practice.

According to the second domain (homework), the item "I give my students homework" had the highest mean among the items in the domain while the item "I tell the students to correct each other's work" had the lowest mean of the items.

There were (2) items that only got high level of practice, and (14) items got medium level of practice, but there weren't any item that got low level of practice.

According to the third domain (exams), the item "I depend on writing exams to evaluate my students" had the highest mean among the items in the domain while the item "I do not pay much attention to the difficulty or ease of the exams' questions" had the lowest mean of the items.

There were (9) items that got high level of practice, and (17) items got medium level of practice, but there weren't any item that got low level of practice.

According to the fourth domain (alternative strategies), the item "I use the observation strategy in evaluating my students" had the highest mean among the items in the domain while the item "I ask my students to do group work evaluation" had the lowest mean of the items.

There were (4) items that got high level of practice, and (12) items got medium level of practice, but there weren't any item that got low level of practice.

Results in Table 3 revealed also that the mean of the (exams) domain was the highest (3.60), then the mean of the (questions) domain was (3.59), then the mean of the (alternative strategies) domain was (3.56) while the mean of the (homework) domain was (3.20) the lowest.

It is noted from Table 3. that the overall mean of the assessment practices equals (3.40), and the standard deviation for these practices is (0.64). Table (2) shows that the average of the assessment practices in the questions domain ranges between (2.48-4.32) with a total mean of (3.59), and the standard deviation for such practices ranges between (1.31-1.31). The table also shows that the average of the assessment practices of mathematics teachers for grades (1-6) in regard to the homework ranges between (2.56- 4.13) with a total mean of (3.20), and the standard deviation for such practices ranges between (1.38-.90).

It is also noted from Table 3 that the most alternative practice in the questions domain is the supervision of the students during answering the questions and exercises with an average of (4.32). Also, table (2) shows that the least assessment practice of teachers in the questions domain is stopping asking the students to write their tasks and solving the problems in the classroom with an average of (2.48).

Second question: Are there any statistically significant differences in the students' learning assessment practices used by Jordanian teachers of mathematics for grades (1-6) that are attributed to the teacher's gender (male and female), teacher's qualification (bachelor, high studies), school type (public, private), training sessions (none, 1-3, more than 3), and experience years (less than5, 5-10, more than 10)?

Means and standard deviations were calculated on each domain of the four domains of the questionnaire and the overall questionnaire according to variables. Levine tests for variance homogeneity were tested, there were not significant, and so significance tests of differences were investigated as shown in Tables 4 to 11 . 
Table 4. Means and standard deviations of the students' responses according to gender and t-test for significance of differences between means

\begin{tabular}{lllllll}
\hline Domain & Gender & $\mathrm{N}$ & Mean & Std. Deviation & t-value & Sig. \\
\hline \multirow{2}{*}{ Questions } & Male & 134 & 50.40 & 9.34 & .263 & .793 \\
& female & 268 & 50.15 & 9.01 & & \\
Homework & Male & 134 & 50.67 & 13.52 & -.636 & .525 \\
& female & 268 & 51.55 & 12.15 & & \\
Exams & Male & 134 & 90.18 & 15.38 & .214 & .830 \\
\multirow{2}{*}{ Alternative strategies } & Male & 134 & 52.75 & 12.09 & -.817 & .415 \\
& female & 268 & 53.83 & 12.73 & & \\
Total & Male & 134 & 244.00 & 46.12 & & \\
& female & 268 & 245.35 & 46.32 & -.276 & .783 \\
\hline
\end{tabular}

Table 4 showed that there are no statistically significant differences in the means of the teacher's responses attributed to gender.

Table 5. Means and standard deviations of the responses according to teacher's qualification and t-test for significance of differences between means

\begin{tabular}{lllllll}
\hline Domain & Qualification & $\mathrm{N}$ & Mean & Std. Deviation & t-value & Sig. \\
\hline \multirow{2}{*}{ Questions } & Bachelor & 290 & 49.10 & 9.13 & $-4.081^{*}$ & .000 \\
& MA \&PhD & 112 & 53.16 & 8.41 & & \\
Homework & Bachelor & 290 & 49.00 & 12.45 & $-6.028^{*}$ & .000 \\
& MA \&PhD & 112 & 57.11 & 11.09 & & \\
Exams & Bachelor & 290 & 86.88 & 15.37 & $-6.579^{*}$ & .000 \\
& MA \&PhD & 112 & 97.86 & 13.98 & & \\
Alternative strategies & Bachelor & 290 & 51.88 & 12.29 & $-4.186^{*}$ & .000 \\
& MA \&PhD & 112 & 57.59 & 12.21 & & \\
Total & Bachelor & 290 & 236.86 & 45.35 & & \\
& MA \&PhD & 112 & 265.71 & 41.86 & $-5.840^{*}$ & .000 \\
\hline
\end{tabular}

Table 5 showed that there are statistically significant differences between the means of the responses in all domains and overall questionnaire according to teacher's qualification, in favor of the higher studies (Master and $\mathrm{PhD})$. 
Table 6. Means and standard deviations of the responses according to school type and t-test for significance of differences between means

\begin{tabular}{lllllll}
\hline Domains & School type & $\mathrm{N}$ & Mean & Std. Deviation & t-value & Sig. \\
\hline \multirow{2}{*}{ Questions } & Public & 330 & 50.65 & 9.08 & $1.990^{*}$ & .047 \\
\multirow{2}{*}{ Homework } & Private & 72 & 48.31 & 9.06 & & \\
\multirow{5}{*}{ Exams } & Public & 330 & 52.25 & 12.52 & $3.413^{*}$ & .001 \\
& Private & 72 & 46.72 & 12.09 & & \\
Alternative strategies & Public & 330 & 90.81 & 15.83 & $2.388^{*}$ & .017 \\
& Private & 72 & 85.94 & 14.93 & & \\
\multirow{2}{*}{ Total } & Public & 330 & 54.56 & 12.42 & $3.799^{*}$ & .000 \\
& Private & 72 & 48.47 & 11.80 & & \\
& Public & 330 & 248.27 & 46.06 & & \\
& Private & 72 & 229.44 & 43.93 & $3.168^{*}$ & .002 \\
\hline
\end{tabular}

Table 6 showed that there are statistically significant differences in the means of the responses in all domains and overall questionnaire according to school type, in favor of the public schools.

Table 7. Means and standard deviations of the responses according to the number of training courses, and one-way ANOVA results

\begin{tabular}{|c|c|c|c|c|c|c|}
\hline Domains & & $\mathrm{N}$ & Mean & Std. Deviation & F- Value & Sig. \\
\hline \multirow{4}{*}{ Questions } & None & 132 & 49.89 & 10.12 & .551 & .577 \\
\hline & $1-3$ & 226 & 50.18 & 8.80 & & \\
\hline & More than 3 & 44 & 51.55 & 7.41 & & \\
\hline & Total & 402 & 50.23 & 9.11 & & \\
\hline \multirow{4}{*}{ Homework } & None & 132 & 51.29 & 13.22 & 2.391 & .093 \\
\hline & $1-3$ & 226 & 51.98 & 11.67 & & \\
\hline & More than 3 & 44 & 47.45 & 14.84 & & \\
\hline & Total & 402 & 51.26 & 12.61 & & \\
\hline \multirow{4}{*}{ Exams } & None & 132 & 89.50 & 16.49 & .230 & .795 \\
\hline & $1-3$ & 226 & 89.92 & 15.45 & & \\
\hline & More than 3 & 44 & 91.36 & 15.40 & & \\
\hline & Total & 402 & 89.94 & 15.77 & & \\
\hline \multirow{4}{*}{ Alternative strategies } & None & 132 & 54.35 & 13.75 & .489 & .614 \\
\hline & $1-3$ & 226 & 53.01 & 11.84 & & \\
\hline & More than 3 & 44 & 53.18 & 12.16 & & \\
\hline & Total & 402 & 53.47 & 12.52 & & \\
\hline \multirow{4}{*}{ Total } & None & 132 & 245.03 & 50.08 & .021 & .979 \\
\hline & $1-3$ & 226 & 245.09 & 44.24 & & \\
\hline & More than 3 & 44 & 243.55 & 44.99 & & \\
\hline & Total & 402 & 244.90 & 46.20 & & \\
\hline
\end{tabular}

It is noted from Table 7 that there are no statistically significant differences in the means of the responses, attributed to the variable of training sessions. 
Table 8. Means and standard deviations of the responses according to experience years and one-way ANOVA results

\begin{tabular}{|c|c|c|c|c|c|c|}
\hline Domains & & $\mathrm{N}$ & Mean & Std. Deviation & F- Value & Sig. \\
\hline \multirow{4}{*}{ Questions } & Less than 5 & 172 & 49.51 & 9.82 & .952 & .387 \\
\hline & $5-10$ & 124 & 50.84 & 8.18 & & \\
\hline & More than 10 & 106 & 50.70 & 8.93 & & \\
\hline & Total & 402 & 50.23 & 9.11 & & \\
\hline \multirow{4}{*}{ Homework } & Less than 5 & 172 & 50.79 & 12.24 & $5.784^{*}$ & .003 \\
\hline & $5-10$ & 124 & 54.15 & 11.92 & & \\
\hline & More than 10 & 106 & 48.64 & 13.42 & & \\
\hline & Total & 402 & 51.26 & 12.61 & & \\
\hline \multirow{4}{*}{ Exams } & Less than 5 & 172 & 89.29 & 14.92 & .273 & .762 \\
\hline & $5-10$ & 124 & 90.24 & 14.76 & & \\
\hline & More than 10 & 106 & 90.64 & 18.17 & & \\
\hline & Total & 402 & 89.94 & 15.77 & & \\
\hline \multirow{4}{*}{ Alternative strategies } & Less than 5 & 172 & 52.99 & 12.12 & .451 & .637 \\
\hline & $5-10$ & 124 & 53.31 & 12.05 & & \\
\hline & More than 10 & 106 & 54.43 & 13.71 & & \\
\hline & Total & 402 & 53.47 & 12.52 & & \\
\hline \multirow{4}{*}{ Total } & Less than 5 & 172 & 242.58 & 45.28 & .604 & .547 \\
\hline & $5-10$ & 124 & 248.53 & 43.24 & & \\
\hline & More than 10 & 106 & 244.42 & 50.98 & & \\
\hline & Total & 402 & 244.90 & 46.20 & & \\
\hline
\end{tabular}

It is noted from Table 8 that there are statistically significant differences in the means of the responses in the domain of homework between 5 and 10 and more than 10. Scheffe test for multiple comparisons was used to indicate the source of this difference as shown in Table 9.

Table 9. Scheffe test for multiple comparisons in the domain of (homework)

\begin{tabular}{llll}
\hline & & Mean dif. & sig \\
\hline \multirow{2}{*}{ Less than 5 } & $5-10$ & -3.35446 & .075 \\
\multirow{2}{*}{$5-10$} & More than 10 & 2.14919 & .378 \\
& More than 10 & 5.50365 & .004 \\
\hline
\end{tabular}

Table 9 showed that the significant difference in the means of the responses in the domain of homework is between (5-10) and (more than 10) in favor of (5-10). And there are no statistically significant differences of the other domains and the overall questionnaire, attributed to the variable of the number of experience years.

\section{Discussion and Conclusion}

The study had a dual purpose: to provide a rich description of basic school Mathematics teachers' for grades (1-6) in practices of assessment and to determine the relationship of these practices with some variables.

Concerning the first purpose, the study found that the most assessment practices used were the exams followed by posting questions while the homework was the least used practice. This might be due to the families' surveillance follow up of the students' scientific achievement. When the families continuously examine the results of their children's tests, the teachers become keen to give the tests their most interests. Additionally, this causes the teachers to post questions during presenting the subjects in order to assure the extent of the students' 
understanding and comprehension. Regarding the realistic alternative strategies, it might be due to the condensed interest of the Ministry of Education in Jordan regarding these strategies within the project of Educational Reform for the Knowledge Economy (ERfKE), and the international trends towards evaluation through subjecting the teachers in training courses and following up their performance by employing such tools and strategies to discover the extent of their comprehensive progress. In general, a comprehensive view of alternative assessment was not found, i.e., lack of adequate understanding of alternative assessment by basic school Mathematics teacher. Regarding the homework, in spite of their importance for improving the learning process, doing them by the student remains questionable in regard to the type of help and the quantity and nature of tasks which may lead the homework to lose its expected benefit.

The research results also show that the least practices in the tests area were the lack of interest in the difficulty or easiness of the questions. This is due to the weakness of the ability to design convincing measuring tools that enjoy credibility and stability functions to be used in discovering the learning of students as well as to the teaching burden on the teachers in the classes which prevents activating this practice and the interest in it.

The results also show that the most used assessment practices in the field of the reformer strategies was supervision of teachers of their students. On the other hand, the least used practice was the group evaluation, and this might due to the availability of tools that can be used in the supervision strategy, such as the crossing list and the ladders of evaluation through training, while the teachers have no idea about how to direct the students to do such evaluation although the evaluation is important for learning.

In the area of asking questions, the most used practice was the teachers' supervision on the students during performing the exercises and solving the problems and the least used practice was the teachers having been stopped asking the students to write their tasks or exercises in the classroom. This is due to the fact that doing such tasks in the classroom is time -consuming, which in turn prevents the teachers from finishing explaining the subject and the details. Consequently, by avoiding this method, they can supervise their students sufficiently during answering the direct class questions.

Regarding the homework, the most used practice was giving the students some pieces of homework while the correction of the students to their tasks was the least used practice. This is due to the fact that there is an agreement on the importance of the homework and the necessity of asking the students between now and then to do such tasks. The teachers do not care about employing the self-correction technique of the homework although it is important in reducing the learning time and improving the learning process indirectly.

Concerning the second purpose, the results show that there are no differences with statistical significance in the assessment practices attributed to the variable of gender. This might be due to the fact that all teachers, males and females, are subjected to the same educational system as well as all the subjects they teach are similar. Additionally, they are subjected to the same training programs during preparing them to service. Accordingly, this study agrees with the studies of (Gasawneh et al., 2009; Hamadneh, 2006; Mafargeh, 2004) while it contradicts with what was reached by (Barakat, 2010; Ali, 2004; Swift, 2002), where the results of their studies show that there is an effect of the gender on the evaluation practices.

The results show that there are differences with statistical significance in the assessment practices attributed to the qualification variable in favor of the higher qualification. These results are attributed to the wide range between the levels of the scientific qualification as they received more comprehensive information which, in turn, affects the evaluation practices. The results of this study agrees with results of (Ghazaleh \& Emhomad, 2004; McNergency, 2003) and contradicts with the results of (Barakat, 2010; Momany \& Khaza'li, 2010; Gasawneh et al., 2009; Hamadneh, 2006).

The study also indicates that there are no significant differences between the assessment practices regarding the variable of the type of the school in favor of the public schools, and this is attributed to the fact that the training implemented by the ministry of education that the public school teachers take in the field of evaluation enable them to use the proper evaluation methods during their teaching according to the various levels of learners which is not available for the teachers of private schools. These results agree with results of (Barakat, 2010; Ali, 2004) which reveal the existence of significant differences in the assessment practices according to the variable of the school's type while they contradict with results of (Kiswani, 2004), which show that there are no significant differences in these practices attributed to the variable of the type of the school.

The results of the study also indicate that there are no differences with statistical significance in the assessment practices of the study's sample according to the variable of the number of training courses. This is attributed to the fact that the teacher is distinguished by special intellectual characteristics, skills, and personal particular features that enable him to employ these practices effectively; in addition, it is also attributed to the influence of 
the training that the teacher takes pre service through the educational and behavioral programs which, in turn, make him able to deal with such practices.

Additionally, these results agree with studies' results of (Barakat, 2010) and contradict with the studies' results of (Wilson, 2001) which show that the teachers who take such training courses are more efficient and effective than the teachers who do not take them because such courses help them to finish their tasks and to follow the developments of the educational process.

The results of this study show that there are differences with statistical significance in the assessment practices attributed to the variable of number of years of experience. This can be attributed to the fact that the teachers acquire evaluation efficiency in small amounts during the years of their service because they actually repeat the same practices regardless of the number of years of experience without the accumulation of qualitative practices. This can be due to the absence of professional growth programs. Additionally, the teacher with less experience receives condensed training courses when he/she enters the teaching profession in order to increase the necessary skills for evaluation and to remove the differences between him/her and the teachers with longer experience. This might be due to the sufficient educational preparation that makes the teacher informed with the evaluation theories and through the mutual visits between teachers.

This result agrees with the studies' results of (Barakat, 2010; Gasawneh et al., 2009; Hamadneh, 2006) while it contradicts with studies' results of (Momany \& Khaza'li, 2010; Almola, 2005), which reveal that there are differences with statistical significance of such practices that are attributed to these experiences.

The results also show that there are no differences with statistical significance in the homework as one of the assessment practices between the groups with a number of experience years ranging between 5-10 years and the group with years of experience exceeding 10 years. The results indicate that there are statistically significant differences in favor of the group with 5-10 years of experience due to the fact that this group depends largely on the performance of their homework, and they follow them up because they grasp the importance of the homework in revealing their level of learning as such practices decrease with the increase of number of years of experience. To emphasize, the increase of tasks prevents the usage of such practices, and this was indicated to in the studies of (Mikk, 2006; Swift, 2002; Cooper \& Valentine, 2001; Wilson, 2001) as well.

The educational reform in Jordan called for encouraging teachers to employ alternative assessment strategies in their classrooms, but according to the findings of this study, it seems that this call has not resulted in any significant change in teachers' practices. Why did the educational reform failed to improve teachers' practices of assessment as expected? The answer to this question may lie in the absence of a dominating culture of assessment practices and the absence of the accountability and the absence of rigged supervisors in the educational system in Jordan. To create such culture, teachers have to be trained during in-service at schools and universities.

Results of the study also revealed the fact that teachers' assessment practices were poor, ambiguous and inconsistent, although the basic school mathematics curriculum guidelines have called for orientation of math teachers to develop assessment strategies, neither the training nor Mathematics district supervisors often have given assessment the concern that it deserves.

\section{Recommendations}

The study presented the following recommendations:

-Training teachers to use alternative assessment strategies and tools in classrooms, such as: peer assessment and self-assessment,

-Improving the quality of the homework and applying it in a suitable way, and improving the quality of the exam questions to cover various types.

-Enhancing the role of students in selecting assessment strategies and suggesting criteria to evaluate their performance.

\section{Acknowledgments}

At the end of this research, we give thanks any personal assistance given, such as in manuscript preparation.

\section{References}

Alberta Assessment consortium. (2005). Conference Handbook. Robert Hogg, Dale Armstrong, Margaret Sanders \& Miranda leader.

Albursan, I., \& Tighza, I. (2012). Evaluation activities used by Mathematics teachers of Saudi Arabian and 
Republic Korea in TIMSS 2007 (Comparative Study). Journal of Education \& Psychology, 39, 401-454.

Ali, M. (2004). The efficiency of Arabic teachers' practicing questioning skill and responding (Unpublished master's thesis). Alnajah University, Nablus, Palestine.

Almola, S. (2005). Design model to evaluate the reality of teaching practices for teachers of physical education at the primary level in the city of Mousel. Retrieved September 14, 2014, from http://www.iraqacad.org/Lib/mousel/shokor.htm

Barakat, Z. (2010). The efficiency of teachers' practicing questioning skill and his responding of the student's questions and answers in classroom. Retrieved September 20, 2014, from http://www.qou.edu/Arabic/r36_drziadBarakat.htm

Brookhart, S. M. (2001). The "standards" and classroom assessment research. Annual Meeting of the American Association of Colleges for Teacher Education, Dallas, TX. Retrieved from the ERIC database (ED451189).

Campbell, C., \& Evans, J. A. (2000). Investigation of preservice teachers' classroom assessment practices during student teaching. The Journal of Educational Research, 93, 350-355. http://dx.doi.org/10.1080/00220670009598729

Cizek, G. (2009). Reliability and validity of information about student achievement: Comparing large-scale and classroom testing contexts. Theory into Practice, 48(1), 63-71. http://dx.doi.org/10.1080/00405840802577627

Cooper, H., Robinson J. C., \& Patall, E. A., (2006). Does homework improve academic achievement? A synthesis of research, 1987-2003. Review of Educational Research, 76(1), 1-62. http://dx.doi.org/10.3102/00346543076001001

Cooper, H., Valentine, J. C. (2001). Using research to answer practical questions about homework. Educational Psychologist, 36(3), 143-153. http://dx.doi.org/10.1207/S15326985EP3603_1

Culbertson, L., \& Wenfan, Y. (2003). Alternative assessment primary grade literacy teachers, attitudes and practices. Annual Meeting of the American Educational Research Association, Chicago.

Eggen, P., \& Kauchack, D. (2004). Educational psychology: Windows on classrooms (6th ed.). New Jersey: Pearson.

Gasawneh, Y., Alayed, W., \& Njadat, M. (2009). The evaluation of educational programs that offered by special classes at school in Taif-cites from the teachers and managers point of view. Retrieved October 3, 2014 from http://faculty.mu.edu.sa/public/uploads.php?fid=17433

Ghazaleh, A., \& Emhomad, O. (2004). Teaching skills among teachers of English in the second part of the basic education level (Unpublished master's thesis). Seventh of April University, Libya.

Green, S. K., \& Mantz, M. (2002, April). Classroom assessment practices: Examining impact on student learning. Annual Meeting of the American Educational Research Association, New Orleans, LA. Retrieved from the ERIC database (ED464920).

Hamadneh, A. (2006). The Extent to which teachers of the Arabic language and its parameters educational competencies necessary to teach high school literary texts and the extent of their exercise in Mafraq governorate. Almanarah Journal, 13(1), 1-57.

Jackson, C. M. (2009). Elementary classroom assessment practices: Method, application, and influent (Ph.D. dissertation, Walden University, Minnesota, USA). Retrieved February 2, 2015 from http://search.proquest.com/docview/305089979

Kiswani, H. (2004). Feeling teacher effectiveness and adjust their belief about students (Unpublished master's thesis). Alquds University, Alquds, Palestine.

Kizlik, B. (2012). Measurement, Assessment, and Evaluation in Education. Retrieved from http://www.adprima.com/measurement.htm

Lamprianou, I., \& Athanasou, J. (2009). A Teacher's Guide to Educational Assessment. The Netherlands: Sense Publishers.

Mafargeh, H. (2004). The characteristics of an effective teacher of Islamic education from the point of view of eleventh grade students in the governorate of Ramallah and Al Bireh (Unpublished master's thesis). Alquds University, Alquds, Palestine.

Mckenna, B. (2004). Classroom assessment: What teachers already know and what they will need to benefit 
Student learning ( $\mathrm{PhD}$ dissertation, University of Massachusetts Lowell, USA).

McNergency, M. (2003). The impact of qualification and experiences on teacher competence. Teacher Journal, 2(7), 61-68.

Mikk, J. (2006). Students homework and TIMSS 2003 mathematics results. Paper presented at the International Conference "Teaching Mathematics: Retrospective and Perspectives," Tartu, Estonia.

Momany, A., \& Khaza'li, Q. (2010). The effect of education and teaching experience on primary female teachers' practice of the international competencies. Dirasat, Educational Sciences, 37(1), 14-31.

Rodriguez, M. (1999). Linking classroom assessment practices to large-scale test performance ( $\mathrm{PhD}$ dissertation, East Lansing: University of Michigan). Retrieved from ProQuest Digital Dissertations.

Stiggins, R. J., \& Conklin, N. F. (1992). In teachers' hands: Investigating the practices of classroom assessment. Albany, NY: State University of New York Press.

Swift, J. (2002). Wait time and questioning skills of middle school science teachers. Roeper Review, 9(2), 64-66.

Wikström, N. (2007). Alternative Assessment in Primary Years of International Baccalaureate Education. The Stockholm Institute of Education, Thesis 15 ECTS.

Wilson, R. (2001). Conceptualizing and validating teacher questioning skills. Journal of Educational and Behavioral Problems, 8(1), 18-24.

Zimmerman, B. J., \& Kitsantas, A. (2005). Homework practices and academic achievement: The mediating role of self-efficacy and perceived responsibility beliefs. Contemporary Educational Psychology, 30, 397-417. http://dx.doi.org/10.1016/j.cedpsych.2005.05.003

\section{Copyrights}

Copyright for this article is retained by the author(s), with first publication rights granted to the journal.

This is an open-access article distributed under the terms and conditions of the Creative Commons Attribution license (http://creativecommons.org/licenses/by/3.0/). 